\title{
Effect of Testosterone on Antler Growth in Male Sambar Deer (Rusaunicolor unicolor) in Horton Plains National Park, Sri Lanka
}

D. S. Weerasekera, N. L. Rathnasekara, D.K.K. Nanayakkara, H.M.S.S. Herath, S.J. Perera, K.B. Ranawana

The authors have withdrawn this manuscript because it underwent a major revision since it was last posted on bioRxiv. However, the preprint number 740936 underwent a major revision since it was last posted on bioRxiv and a link to the published article in the journal BioMed Research International with a revised title as "The antler cycle and fecal testosterone of male sambar deer Rusa unicolor unicolor at the Horton Plains National Park in Sri Lanka" is forthcoming. The peer review process resulted in changes to the title as well as the methods, results and conclusions sections of the preprint. Therefore, the authors do not wish this work to be cited as reference for the project. If you have any questions, please contact the corresponding author.

Corresponding:danushw2@gmail.com

D. S. Weerasekera 